\title{
The Syntax of Sentential Negation in Jordanian Arabic
}

\author{
Islam M. Al-Momani \\ Al-Hussein Bin Talal University, Jordan \\ Email: almomani_islam@yahoo.com
}

\begin{abstract}
This paper attempts to present a clear picture about sentential negation in Jordanian Arabic. It aims at describing the various aspects of sentential negation by showing how negation operates with different negative particles and by illustrating the different positions of these particles and their behavior in sentences. It also attempts to shed some light upon the classification of the negative particles according to their occurrences in sentences, i.e., verbal and non verbal sentences and according to their syntactic positions in these sentences. This paper takes into consideration the interchangeability of certain negative particles by others with or without resulting in different sentence meaning. The examples throughout this study are taken from daily life conversations of Jordanians and considered the corpus this study aims to describe.
\end{abstract}

Index Terms - Jordanian Arabic, negation, negative particles, word order, copular sentences

\section{INTRODUCTION}

The goal of linguistic study is to discover the nature of language, how it is acquired and how it functions. The study of syntax is, in particular, concerned with the ways in which lexical items are organized hierarchically by operations into grammatical phrases and clauses. These operations are regulated by principles of the syntactic "module" of the linguistic system in order to uncover the structural principles governing these operations cross-linguistically. Therefore, the underlying universal principles of all languages may be discovered by showing how they are different in certain restricted parametric ways. These universal principles common to all languages comprise what is known as (Chomsky's term) Universal Grammar (UG), i.e., the system innate to the human brain which allows for the acquisition of language.

In recent years, much attention has been given to the question of how best to represent the structure of negative phrases and the nature and the structures of negators themselves. Negation data in various languages give many significant inferences about the underlying structural principles of negation.

Negation is a universal notion. Indeed, it is one of the most basic elements in human mind that makes it an indispensible part of natural languages which are the tools for human thoughts. Every language has negative particles or expressions; statements that involve negative particles are called negative statements. As it is known, negation is the opposite of affirmation; one sentence or statement can be the negation or denial of another. Thus, negation is the process of making a sentence negative usually by adding negative particles. According to Gleason (2001), this allows us to discuss what is not happening, or what we do not want. Bloom (1970) suggests that when children are learning a language, it is likely that they learn to produce and distinguish between two basic types of sentences: the affirmative and the negative.

Negation is a fundamental linguistic phenomenon for the whole language system in Jordanian Arabic. It appears at different syntactic levels and has different purposes or meanings. Brustad (2000) studies negation in four Arabic dialects from a dialectological point of view. These four Arabic dialects are: Egyptian Arabic (EA), Moroccan Arabic (MA), Syrian Arabic (SA), and Kuwaiti Arabic (KA). She states that the four dialects have three strategies of negation: verbal negation, predicate negation, and categorical negation. She has also defined Categorical negation in these dialects as that kind of negation which is not restricted to a single entity or two of the category but includes the whole category which, according to her, doesn't mirror the mood of the speaker but has a normative aspect that is arrived after witnessing the negation of a certain relationship, incident, member of a group, etc. Abulhaija (1989) studies the acquisition of negation by Jordanian children, and has stated that negation consists of linguistic structures that permit:

a. the either conjoining

b. not even

c. tag questions without no

Emphatic negation has been termed by him in the same way as in Bustard definition of categorical negation and claims that it is directive in nature and reflects the mood of the speaker.

Negation in Arabic has been studied extensively, but most of it has been in the form of syntactic analysis. Some of the studies are done by Eid (1991), Benmamoun (1996 and 2000), Fassi Fehri (1993), Bahloul (1996) and many others. Al-Tamari (2001) studies sentential negation from a syntactic perspective adopting the minimalist approach. He attempts to show how sentential negation in verbal and verbless sentences is formed in English, Standard Arabic, and 
some dialects of Arabic including Jordanian Arabic. Due to the nature of his study, Al-Tamari hasn't covered many aspects of negation including categorical negation.

Onizan (2005) attempts to study negation from a pragmatic perspective by providing negative utterances in Arabic literary discourse in both Modern Standard Arabic and Jordanian Arabic. Onizan's research has not included the pragmatic variations of negation morphemes which have the influence of determining the relationship between conversationalists and the speech tone.

\section{OBJECTIVES AND METHODOLOGY}

This articles aims at investigating sentential negation in JA. It aims at answering the following research questions:

a. How does negation operate with different negative particles?

b. What are the different positions of these particles and their behavior in JA sentences?

c. Can the aspects of sentential negation in JA be straightforwardly accounted for in light of derivation and featurechecking principles of the minimalism approach?

d. Are negators heads of independent projections?

e. How are negative items interpreted?

f. What governs their distribution?

The researcher follows the descriptive- analytical approach. The data used here is an amalgamation of genuine sentences uttered by native speakers of JA. As for the MSA data, authentic grammar books are used as sources, in addition to that, a few Arab grammarians are referred to for their consultation, and testing the validity of the data.

The following symbols are used to represent certain Arabic sounds that don't match IPA symbols.

/T/ voiceless alveo-dental emphatic stop

/ḍ / voiced alveo-dental emphatic stop

/ș / voiceless alveolar emphatic fricative

$/ \mathrm{h} /$ voiceless pharyngeal fricative

/c/ voiced pharyngeal fricative

/q/ voiceless uvular stop

$/ \dot{\mathrm{g}} /$ voiced velar fricative

/ $\mathrm{x} /$ voiceless velar fricative

\section{DISCUSSION}

\section{A. Negation in Jordanian Arabic}

Based on the aforementioned studies, this paper attempts to present a unitary description of negation in Jordanian Arabic (JA). The pragmatic variations of negation morphemes, their use and their functions, the morphological phenomenon of negation and the syntactic analysis of negation will be presented in this paper. The types of negation discussed here are not comprehensive because this paper doesn't cover all the strategies of negation; for example, negative questions are not discussed here.

The system of negation in JA is neither straightforward nor simple. My aim in this paper is to determine the present distribution of negative particles in JA and to suggest how this distribution may have arisen. There are four negative particles used for sentential negation in JA: 'ma', 'ma... J', 'mil' and 'laa'. In general these particles are immediately pre-verbal. Most of the current works on sentential negation have adopted what is known as 'the Neg.P Hypothesis', which is assumed to be the correct analysis of sentential negation (see among others, Pollock (1989), Kayne (1989), Zannuttini (1990), Chomsky (1991) Laka (1994) and Haegeman (1995). This hypothesis is adopted by Brustad (2000), Benmamoun (1992; 2000), Shlonsky (1997), and Ouhalla (1991) of different Arabic dialects.

According to this hypothesis, negative particles head their own functional projections as illustrated in (1).

(1).

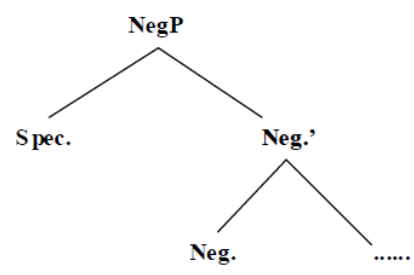

This hypothesis is a result of a more general hypothesis known as 'Split Inflection Hypothesis' which was first suggested by Pollock (1989) and later adopted by Chomsky (1991, 1995), and Benmamoun (1992, 2000). According to this hypothesis, tense, negation and agreement are represented as syntactic projections independent of their 'morphophonological' host (predicate). 
It is reasonable, in this paper, to follow this hypothesis and claim as claimed by Benmamoun (2000) that the negative particle in JA is a head element and it heads its own syntactic projection, and sentential negation occupies the position between TP and VP.

\section{The Negative Particle 'ma. .. . ' or/and 'ma'}

One of the negative particles used to negate verbal sentences in JA is the discontinuous morpheme ma. . . 0 or 'ma' without the suffix. According to Onizan (2005), the negative particle ma. . . $\int$ is equally used in both perfective and imperfective aspects of the verb as can be seen in sentences (2) and (3) respectively. The only difference between these two negative particles is that 'ma.. S' cannot be used with the infinitive mode to express the future tense, whereas 'ma' can. This explains the ungrammaticality of sentence (4) and the grammaticality of sentence (5) respectively.

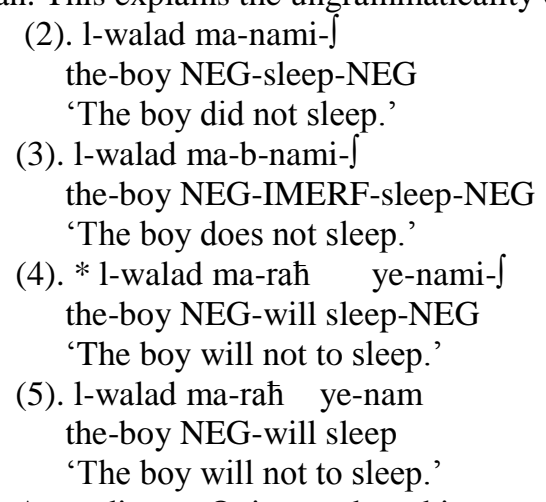

According to Onizan, when this negative particle is used to negate a group of light verbs or pseudo verbs which are, by nature, prepositional phrases and adverbials functioning like verbs, the first part of the particle becomes optional. Consider the following examples taken from Onizan (2005):
(6). (ma)-bad-haa-f xubiz (NEG)-want-she-NEG bread 'She does not want bread.'

(7). (ma)-ma?-haa-J fluus

(NEG)-with-her-NEG money

'She does not have money.'

It is worth mentioning that the negative particle 'ma. . . J' does not behave identically regarding aspect. When the verb is in the perfective mode, negation can be formed by the two parts of the morpheme as seen in (2) above or by the first part alone as in (8).

(8). 1-walad ma-nam the-boy NEG-sleep

'The boy did not sleep.'

Negation formed by the second part alone leads to the ungrammaticality of the sentence as in (9).

(9). *l-walad nami-

the-boy sleep-NEG

'The boy did not sleep.'

When the verb is in the imperfective mode, negation can be formed by three options: the two parts of the morpheme as in (3); the first part of the morpheme alone; and the second part of the morpheme alone as in (10), and (11) respectively.

(10). 1-walad ma-bi-nam the-boy NEG-IMERF-sleep

'The boy does not sleep.'

(11). l-walad bi-nami- $\int$ the-boy IMERF-sleep-NEG

'The boy does not sleep.'

Accordingly, the deletion of one of the suffixes of the negative particle 'ma. . . ' is associated to the type of the verb. It seems here that ' $m a$ ' is associated to the negation of perfective verbs, while in imperfective verbs either part of this discontinuous morpheme 'ma' or $\int$ is possible.

Two meanings can be presented if the suffix ' $\int$ ' is deleted. One meaning, presented by Abulhaija (1989) for Jordanian Arabic, is emphatic negation, while another meaning, presented by Brustad (2000) for Moroccan and Egyptian Arabic, is categorical negation. They propose that the deletion of this suffix indicates emphasis or absolute negation. However, the conditions they presented for the occurrence of each kind of negation are nearly identical. Nonetheless, I believe that categorical negation is more or less impersonalized while emphatic negation is personalized and reflects the person's point of view. In terms of frequency, I also believe that the negative particle in its two parts is the most common means of verbal negation among the speakers of Jordanian Arabic. 
According to Al-Tamari (2001), Jordanian Arabic uses the negative particle 'ma' to negate perfective and imperfective verbs. He states that 'ma' and 'ma. . . .' are syntactically generated in the same position and in terms of function, they serve the same function. Thus, sentences (2) and (3) are repeated in (12) and (13) with only the negative marker 'ma'.

(12). l-walad ma-nam the-boy NEG-sleep

'The boy did not sleep.'

(13). l-walad ma-b-nam the-boy NEG-IMERF-sleep

'The boy does not sleep.'

Thus, in JA the suffix ' $\int$ ' is optional. The only difference is that 'ma... 'can be used in the future tense as explained earlier in this section.

'ma. . . .' or 'ma' can also be used for denial in discourse and can occur in the context of both past and present with verbal predicates.

(14). a. ma-ba-drusi-f

NEG-I-study-NEG

'I do not study.'

b. ma-ba-drus

NEG-I-study

'I do not study.'

This is an answer to a question in the present tense; whereas, the examples in (15) are an answer to a question in the past tense.

(15). a. ma-darasti-f

NEG-I-study-NEG

'I do not study.'

b. ma-darasit

NEG-I-study

'I do not study.'

The negative particle 'ma' or its variant 'ma... ' can be treated as the head of its syntactic projection and can host subject clitics which is a property of heads. This situation is attained in JA as shown in the paradigm in (16).

\begin{tabular}{ll} 
(16). ma-nii- $\int$ & \multicolumn{1}{c}{ I + NEG } \\
ma-ntaa- & you.M.S + NEG \\
ma-ntii- $\int$ & you.F.S + NEG \\
ma-huu- $\int$ & he +NEG \\
ma-hii- $\int$ & she + NEG \\
ma-hnaa- & we + NEG \\
ma-ntuu- $\int$ & you.P. + NEG \\
ma-hummi- $\int$ & they + NEG
\end{tabular}

The same situation is accomplished in various dialects of Arabic as in the paradigms provided for Egyptian Arabic ( Eid 1991), Moroccan Arabic (Caubet 1996), and Kuwaiti Arabic (Brustad 2000).

Therefore, it is reasonable to conclude that in JA verbal negation is achieved when the negative particle 'ma... ' or ' $m a$ ' is attached to the verb, i.e., the negative particle is hosted by the verb. Now, if we proceed with the claim made by Brustad (2000), Benmamoun (1992; 2000), Shlonsky (1997), and Ouhalla (1991) of different Arabic dialects that this particle heads its own syntactic projection, the verb merges with negation, taking into consideration that sentential negation occurs between TP and VP. The subject and the verb are located under the Spec(ifier) and the head of the VP respectively. This can be shown in the following tree diagram:

(17). 


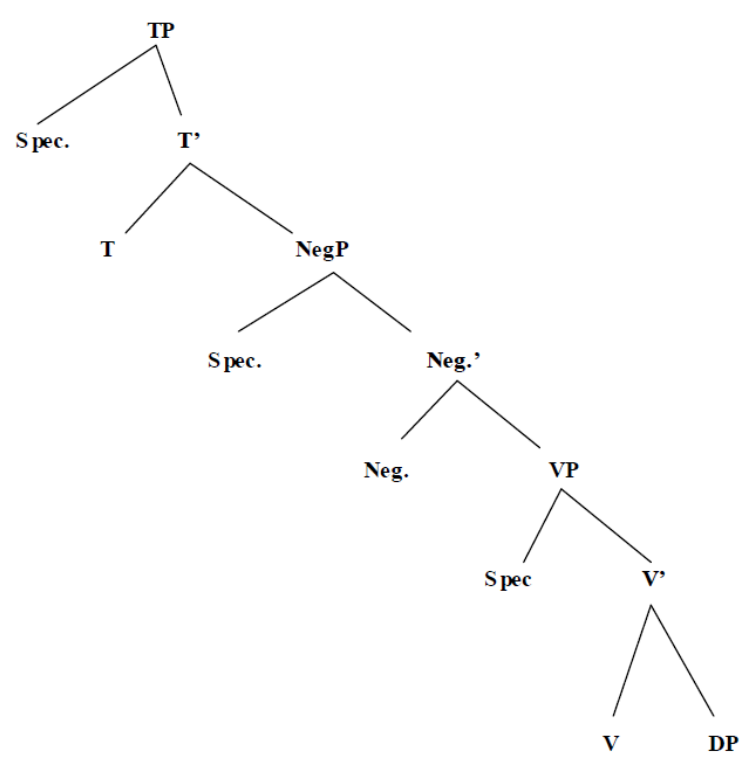

To account for the merger between the verb and the negative particle, I will adopt Benmamoun's (2000) comprehensive analysis of sentential negation in Arabic within the framework of the minimalist program. He assumes that Neg. is specified for [+D] feature which attracts the verb as a potential checker, and argues that the agreement on the verb can check the [+D] feature. According to him, this is one important factor that motivates the movement of the verb. The other factor that motivates the movement of the verb is the $[+\mathrm{V}]$ feature of $\mathrm{T}(\mathrm{ense})$ which attracts the verb to raise and check the $[+\mathrm{V}]$ feature. He argues that only in the past tense, $\mathrm{T}$ is specified for verbal and nominal features $([+\mathrm{V},+\mathrm{D}])$. Thus, in sentential negation, the verb raises to Neg., merges with the negative particle and checks the [+ D] feature of Neg. and then the complex head [Neg. + V] moves to T to have its [+ V] feature checked. Since the verb is already in T, it checks T's [+ D] feature. This analysis will result in the VSO word order. To justify this analysis in JA, consider (18) and its representation in (19).

(18). ma-ḍ arabi- $\int$ 1-mcallim 1-walad

NEG-hit-NEG the-teacher the-boy

'The teacher did not hit the boy.' (19).

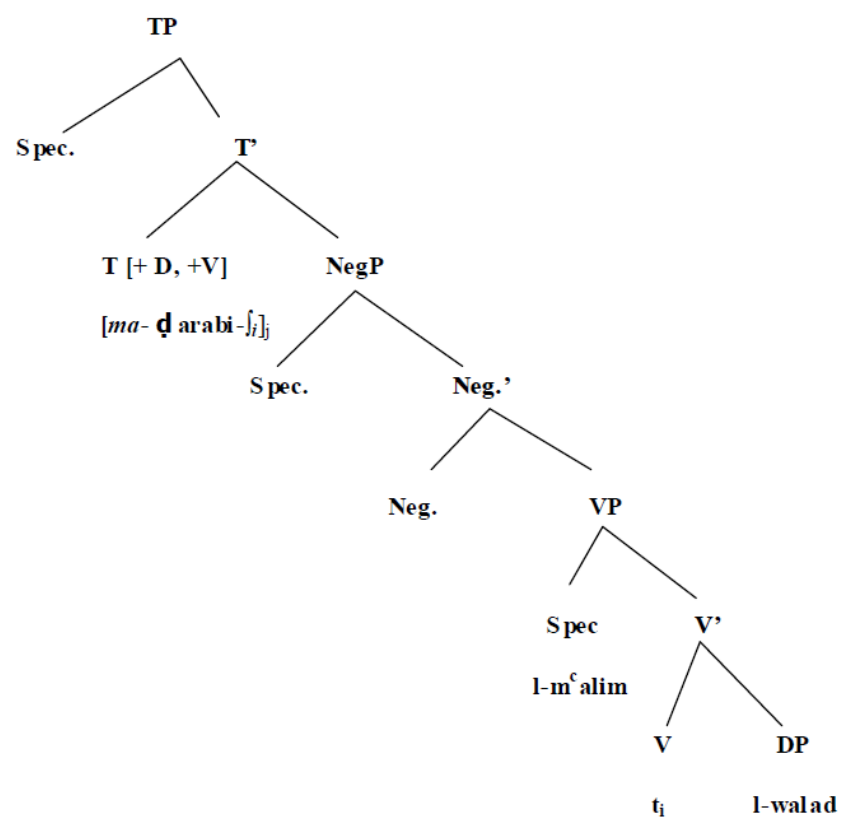

Regarding SVO order in Arabic, Benmamoun argues that the subject which is a primary checker of the [+ D] feature of $\mathrm{T}$ moves to the Spec. of TP via the Spec. of Neg.P to check the [+ D] feature of T. In present tense sentences, T doesn't attract the verb to raise because it lacks the $[+\mathrm{V}]$ feature. However, the merger with Neg. can be justified by the fact that Neg. is specified for the [+D] feature, which attracts the verb as a possible checker. Since the [+ D] feature of 
$\mathrm{T}$ is not checked by the verb, the subject moves to the Spec. of TP through the Spec. of Neg.P to check the nominal feature of T, i.e., [+D]. Consider (20) and its representation in (21) in JA.

(20). 1-mcallim ma- d arabi- 1 l-walad
the-teacher NEG-hit-NEG the-boy
'The teacher did not hit the boy.'
(21).

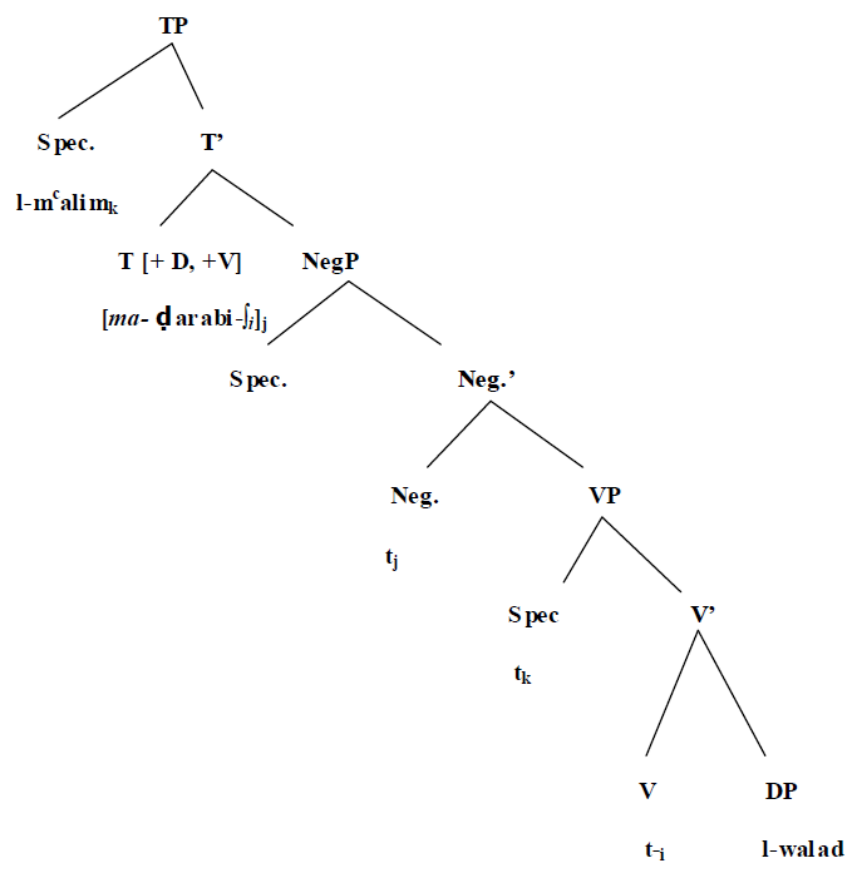

The derivation of the VSO negative sentences in the future tense in JA is justified exactly the same way as in the past tense. Consider sentence (22) and its representation in (23).

(22). Maher ma-rah-ye-lcab 1-korah

Maher NEG-will-play the-football

'Maher will not play football.

(23).

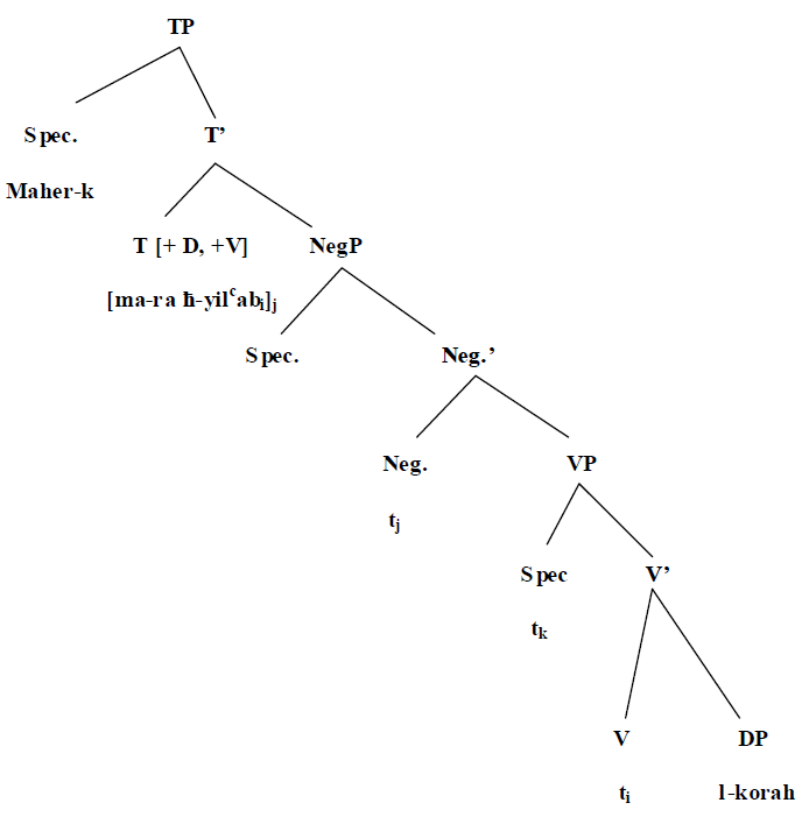

According to this representation, the verb (rah-yilcab) raises to Neg. then the complex head [ma-rah-yilcab] raises to T to have the $[+\mathrm{D}]$ feature checked.

In sum, Benmamoun's analysis successfully accounts for sentential negation in JA in verbal sentences. 


\section{The Negative particle 'mil'}

'mil' is another negative particle occurs in present and future, accompanying verbal predicates as well as non-verbal predicates. When the negative marker ' $\mathrm{mi}$ ]' is used to negate future sentences, it must contain the infinitive mode as in (24).

$$
\text { (24). Ali mil rah-yinjah bi-l-?imtihan bukrah }
$$

Ali NEG going to pass in-the-examination tomorrow

'Ali is not going to pass the examination tomorrow.'

(25). ?ana mi bahib-ha

I NEG love- her

'I do not love her.'

In non-verbal predicates (nominal sentences), Abulhaija (1989) proposes that the negative particle 'mil', in addition to negate future sentences, is also used in JA to negate nominal sentences. Sentences (26), (27), and (28) are examples of nominal sentences negation.

(26). huu mif fi-l-beit

he NEG in-the-house

'He is not at home.'

(27). Ahmad mil naleeT

Ahmad NEG active

'Ahmad is not active.'

(28). Ahmad mif Talib

Ahmad NEG student

'Ahmad is not a student.'

The negative particle 'mif' in JA is one single non-discontinuous particle, i.e., the separation between 'mi' and ' $\int$ ' will lead to the ungrammaticality of the sentence as shown in (29).

(29). *Ahmad mi naleeT-J

Ahmad NEG active-NEG

'Ahmad is not active.'

This result is consistent with Brustad's (2000) analysis; she argues, while studying Egyptian Arabic, that the negative particle 'mil' is non-discontinuous and cannot be separated.

A specific question is to be addressed here:

Is there a deleted copula in verbless sentences in MSA as well as in other dialects of Arabic including JA?

In order to answer this question, this paper provides three analyses which are suggested to account for the absence of the copula in verbless sentences. The first one is done by Baker (1980) and Obeidat and Farghal (1994). They suggest that in verbless sentences there is always a copula that undergoes a deletion process under certain circumstances. According to them, the copula is lexically realized at D. Structure but gets deleted during the derivation if the conditions for deletion exist.

The second analysis is made by Fassi Fehri (1993). He assumes that the copula exists in the derivation as a null verb which is not realized phonologically.

Benmamoun (2000) provides the third analysis which is going to be adopted here. He suggests that verbless sentences do not contain a null copula or undergo a copula deletion rule. He assumes that since verbless sentences are in the present tense, we do not have to assume that there is a null copula that hosts the tense because the present is only specified for the $[+\mathrm{D}]$ feature. He assumes the following structure:

(30).

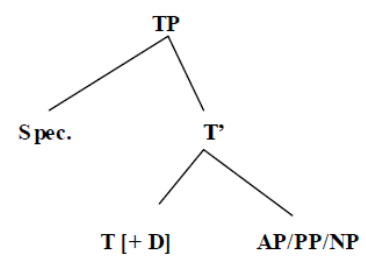

Accordingly, JA doesn't allow merger between the negative particle mif and nouns, adjectives and prepositional phrases that follow. Thus, the representation of sentence (28) is as in (31).

(31). 


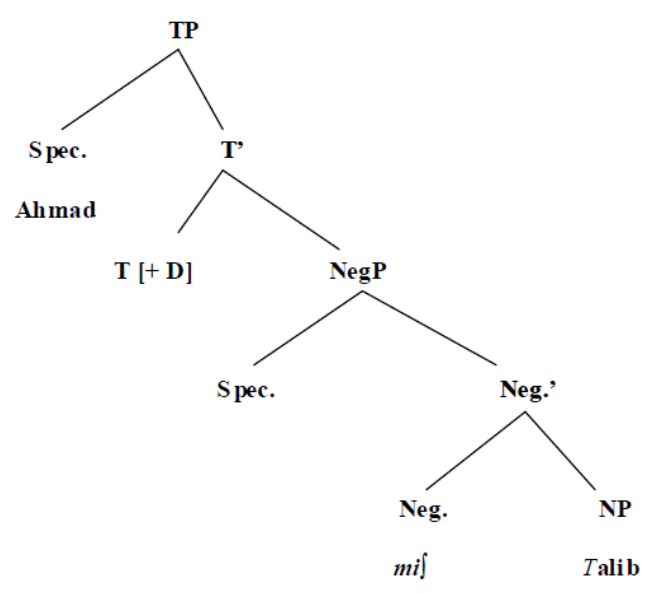

\section{The negative particles 'laa'}

The most straightforward of the JA negative particles is 'laa'. It is a future oriented particle used before the verb, and occurs only in negative commands. Therefore, the particle 'laa' in MSA as well as in JA has a prohibitory sense and thus called the 'laa' of prohibition. Consider the following example from MSA:

(32). laa ta?kul wa anta waqif-un

NEG eat-2MS and you stand-nom

'Do not eat while standing.'

In JA, prohibitives can be formed in different ways by using different negative particles: (1) using the particle 'laa' before the verb as it's the case in MSA as in (33), (2) positioning 'laa' before the verb and the suffix ' $f$ ' after the verb as in (34), (3) using the suffix ' 9 ' alone after the verb as in (35).

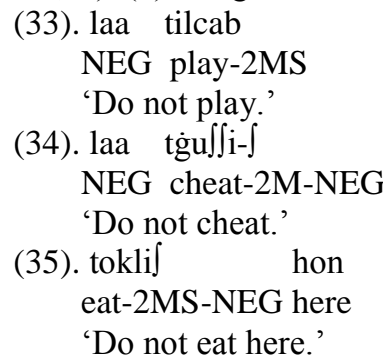

The negative particle 'ma....' or its variant 'ma' can also be used to negate imperative sentences. Consider the examples below where the bound morpheme 'ma' occurs before the verb and the suffix ' $f$ ' after the verb as (36). The morpheme 'ma' is used alone before the verb as in (37). Again as in the case of the negative particle 'laa', the suffix 'f ' of the discontinuous morpheme 'ma...'.' may occur alone after the verb as in (38).

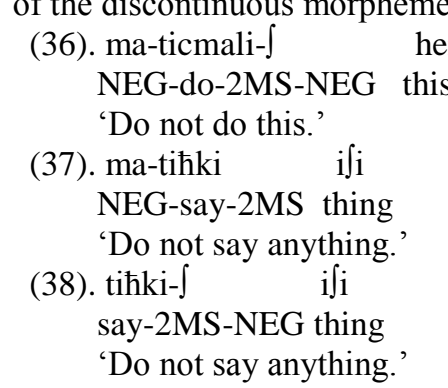

Thus, as can be noticed in the examples above, the negative particle 'ma... .' can either be used with the presence or the absence of the suffix ' ' ' or this suffix can be used alone.

Accordingly, two claims can be offered regarding this. The first one is due to the fact that there are two negative morphemes used within the same sentence namely, the bound morpheme 'ma' and the suffix ' $'$ '; thus, the absence of either is to avoid repetition. The other claim is restricted to the absence of the suffix ' ' '; in fact, the omission of this suffix carries the meaning of total prohibition, emphasizes the negation, warns the person, or even a punishment if broken. Consider the following sentences said by a teacher addressing his student:

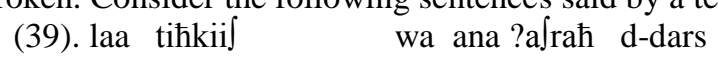

NEG talk-2MS-NEG while I explain the-subject

'Don't talk while I am lecturing.

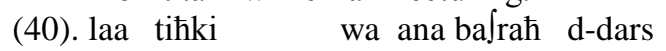

NEG talk-2MS while I explain the-subject

'Don't talk while I am lecturing. 
(39), and (40) are prohibitives. The only difference between them, which indicates a difference in meaning, is the presence and the absence of the negation suffix ' $\int$ '. (39) which contains the negation suffix ' $\int$ ', a lenient form of prohibition is used by the teacher when he asks his student not to talk while the class is going on. However, (40) has a stronger form of prohibition because it lacks that negation suffix. Thus, the negation suffix carries another meaning in addition to negation, i.e., leniency.

The negative particle 'laa' in JA occurs only in the present tense. The present tense in Arabic, according to Benmamoun (2000), is not morpho-phonologically realized and thus, does not carry the tense. He also argues that the present tense features are different from the past tense features because the present tense is specified for nominal features $[+\mathrm{D}]$ only.

The negative particle 'laa' requires the verb to be an infinitive and must be adjacent to the verb. This explains the grammaticality of (41) and the ungrammaticality of (42) and (43).
(41). laa tilcab bi-l-korah
NEG play-2MS with-the- football
'Do not play football.'
(42). *laa licib bi-1-korah
NEG played-2MS with-the-football
'Did not play football.'
NEG with-the- football play-2MS
'Do not play football.'
(43). *laa bi-1-korah tilcab

In JA, 'laa', is like the negative particle 'ma...', , heads a negation between TP and VP. Since 'laa' occurs only in the present tense, it stays in its position and does not have to merge with any functional element. It is spelled out as the default tenseless negative 'laa'. Consider (44) and its illustration in (45).
(44). laa tibki
NEG cry $2 \mathrm{MS}$
'Do not cry.'

(45).

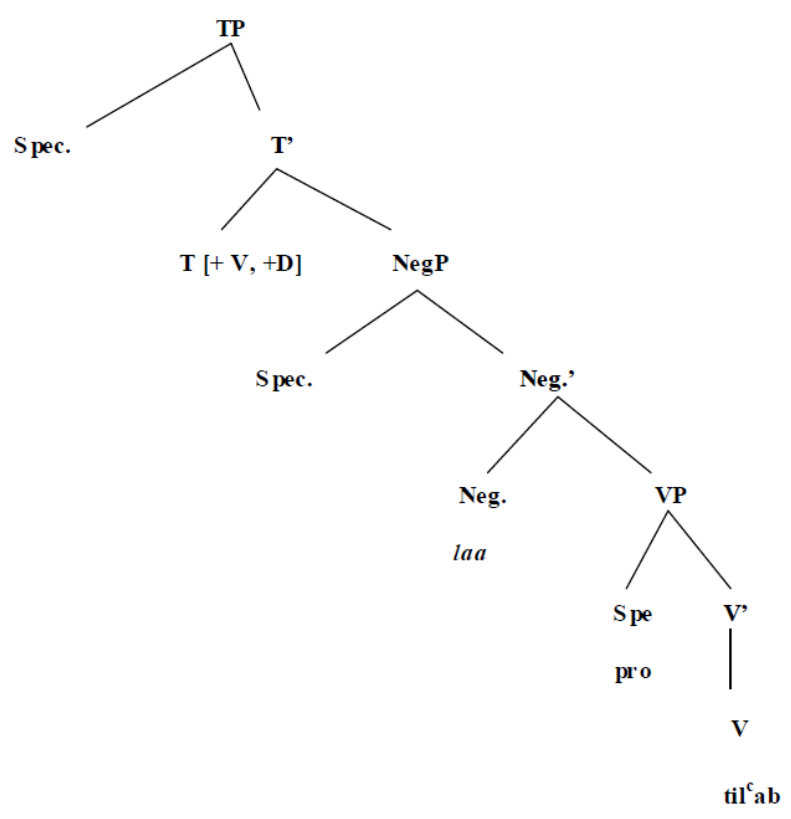

\section{B. Negation of Copular Sentences}

Copular sentences are defined as those sentences that contain a copula. In JA as well as in Modern Standard Arabic (MSA), the copula 'kaan' with its different morphological realizations of tense, person, number and gender must be present in the past and the future tense. Before discussing negation of copular sentences in both languages: MSA and JA, it is necessary to indicate that the modern dialects of Arabic including JA have impoverished the inflectional system in comparison to MSA. Word order in MSA is rather more relaxed due to its rich overt Case marking. A sentence, for instance, that has a two place predicate in MSA could have six acceptable word orders as can be seen below.
(46). ?akala l-kalb-u l-lahm-a ate-3MS the-dog-nom the-meat-acc
'The dog ate the meat.'
(47). ?akala 1-la hm-a l-kalb-u 
Ate-3MS the-meat-acc the-dog-nom

'The dog ate the meat.'
(48). 1-kalb-u ?akala
1-laћm-a
the-dog-nom ate-3MS the-meat-acc
'The dog ate the meat.'
(49). 1-kalb-u l-lahm-a ?akala
the-dog-nom the-meat-acc ate-3MS
'The dog ate the meat.'

(50). 1-lahm-a ?akala 1-kalb-u

the-meat-acc ate-3MS the-dog-nom

'The dog ate the meat.'
(51). 1-lahm-a l-kalb-u ?akala
the-meat-acc the-dog-nom ate-3MS
'The dog ate the meat.'

Moreover, in SVO word order, the verb shows full agreement features with the subject; whereas, in VSO word order, the verb shows partial agreement features with the subject, i.e., missing number agreement.

(52). nama 1-?awlad-u

slept-3MS the- boys-nom

'The boys slept.'

(53). 1-?awlad-u naamu

the-boys-nom slept-3MP

'The boys slept.'

In contrast, the dialects of Arabic have a rigid word order due to the absence of Case marking and reduced feature agreement. When there is not enough Case marking to distinguish between the subject and the object, word order is reduced to SVO and VSO.

(54). qatal ș -ș ayyad l-asad

kill-3MS the-hunter the-lion

'The hunter killed the lion.'

(55). ș -ṣ ayyad qatal 1-asad

the-hunter kill-3MS the-lion

'The hunter killed the lion.'

(54) is represented as in (56).

(56).

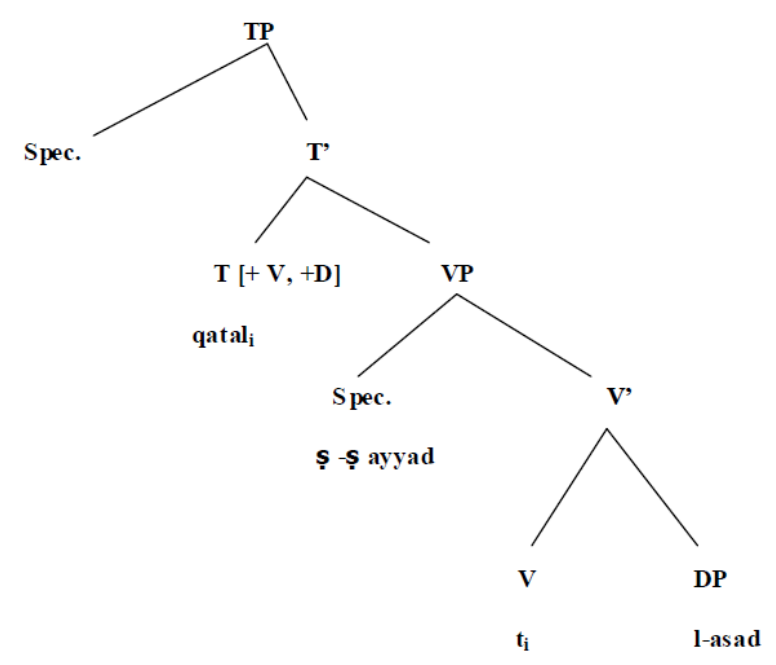

(55) is represented as in (57).

(57). 


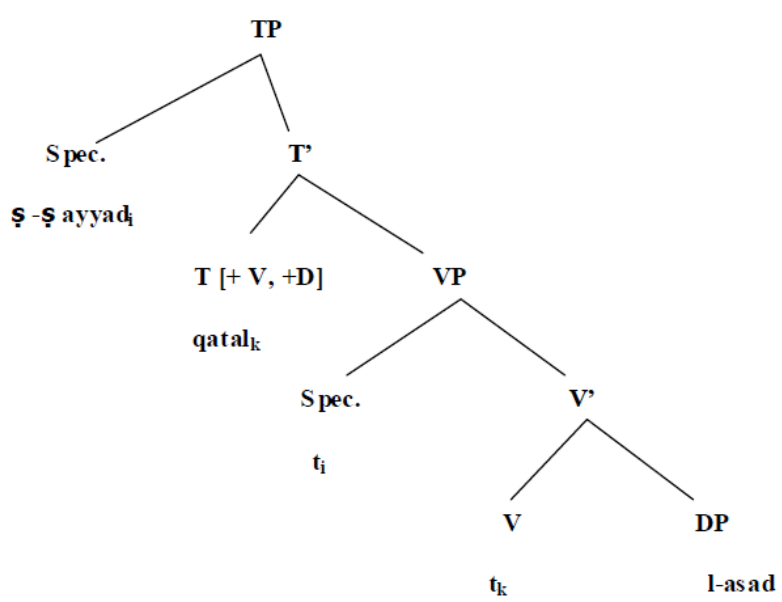

While VSO word order is preferred by the speakers of JA in the past tense sentences, SVO word order is preferred in present tense sentences.

In VS order in MSA, the copula agrees with the subject in gender and in person, and the complement has to bear accusative case, while in SV, the copula agrees with the subject in person, number and gender, and the complement again has to bear accusative case. Consider the following examples:

(58). kaan-a l-imttihan-u sahl-an

was-3MS the-examination-nom easy-acc

'The examination was easy.'

(59). sa-yakuun-u l-imttihan-u sahl-an

will-M-be the-examination-nom easy-acc

'The examination will be easy.'

(60). kaan-a T-Tullab-u fi-1-madrasat-i

was-3MS the-students-nom in-the-school-gen

'The students were in the school.'

(61). T-Tullab-u kaan-u fi-l-madrasat-i the-students-nom were.them in-the-school-gen

'The students were in the school.'

Depending on aspect and tense, there are three different ways that can be used to negate copular constructions in MSA. The three different negative particles used are: (1) 'ma' which is used to negate past perfective forms, (2) 'lam' used to negate past imperfective forms, and (3) 'lan' to negate the future. Consider the followings:

(62). ma kaan-a T-Taqs-u jamiil-an

NEG was-MS the-weather-nom beautiful-acc

'The weather was not beautiful.'

(63). lam yakun T-Taqs-u jamiil-an

NEG was-MS the-weather-nom beautiful-acc

'The weather was not beautiful.'

(64). lan yakuun-a T-Taqs-u jamiil-an

NEG M-be-MS the-weather-nom beautiful-acc

'The weather will not be beautiful.'

In MSA, the copula doesn't appear in present tense sentences. They exhibit the following patterns: (1) a subject (NP) and a predicate (NP, AP, PP) as in (65a, b, and c), a subject (NP), a pronoun and a predicate (NP, PP) as in (66), (3) a subject (NP) and a predicate (NP, AP) as in (67a and b). In either case the subject has to be definite and as far as case and agreement are concerned, the subject and the predicate agree in Case (nominative), number and gender.

(65). a. Hind-un Taaliba-t-un

Hind-nom student-F-nom

'Hind is a student.'

b. Hind-un jamila-t-un

Hind-nom beautiful-F-nom

'Hind is beautiful.'

c. Hind-un fi-l-manzil-i

Hind-nom in-the-house-gen

'Hind is at home.'

(66). a. Hind-un hiya T-Taalibat-u

Hind-nom 3FS the-student-F-nom

'Hind is the student.' 
b. Hind-un hiya fi-1-manzil-i

Hind-nom 3FS in-the-house-gen

'Hind is at home.

(67). a. Hind-un T-Taalibat-u

Hind-nom the-student-F-nom

'Hind is the student.'

b. Hind-un j-jamila-t-u

Hind-nom the-beautiful-F-nom

'Hind is the beautiful girl.'

In certain contexts, the copula appears in present tense constructions, but the time reference is future. That is the speaker is making a prediction as in (68).

(68). yakuun-u s-safar-u mutcib-an bi-l-qitar-i

M-be-3S the-travel-nom tiresome-acc by-the-train-gen

'Traveling by train will be annoying.'

In (68), the speaker is making a kind of prediction about how traveling is going to be by train. The same sentence is also possible without the copula as in (69).

(69). s-safar-u mutcib-un bi-1-qitar-i

the-travel-nom tiresome-nom by-the-train-gen

'Traveling by train will be annoying.'

Regarding negation in the present tense sentences, none of the particles mentioned above, which are tense oriented, can be used. Instead, the negative particle 'laysa' (not) is used. This negative particle agrees with the subject in number and gender, and its complement has to bear accusative case.

(70). laysa l-walad-u mujtahid-an

NEG-3MS the-boy-nom diligent-acc

'The boy is not diligent.'

(71). laysat l-bintu mujtahidat-an

NEG-3FS the-girl-nom diligent-F-acc

'The girl is not diligent.'

'laysa' behaves like a verb because it cannot co-occur with the verb copula and it has the same grammatical function with respect to case assignment as the copula, i.e., they both assign their complements accusative case.

(72). kaan-a r-rajul-u mariiḍ -an was-3MS the-man-nom sick-acc 'The man was sick.'

(73). *laysa kaan-a r-rajul-u mariị̣ -an

NEG Was-3MS the-man-nom sick-acc

'The man was not sick.'

(74). laysa r-rajul-u mariị̣ -an

NEG-3MS the-man-nom sick-acc

'The man was not sick.'

However, the negative particle 'laysa' and the copula are different in two ways: first, 'laysa' is inherently [+ present]; whereas, the copula can be used in the past, present and future. Second, unlike the copula, 'laysa' is inherently negative.

Sentence (74) can be represented as in (75).

(75).

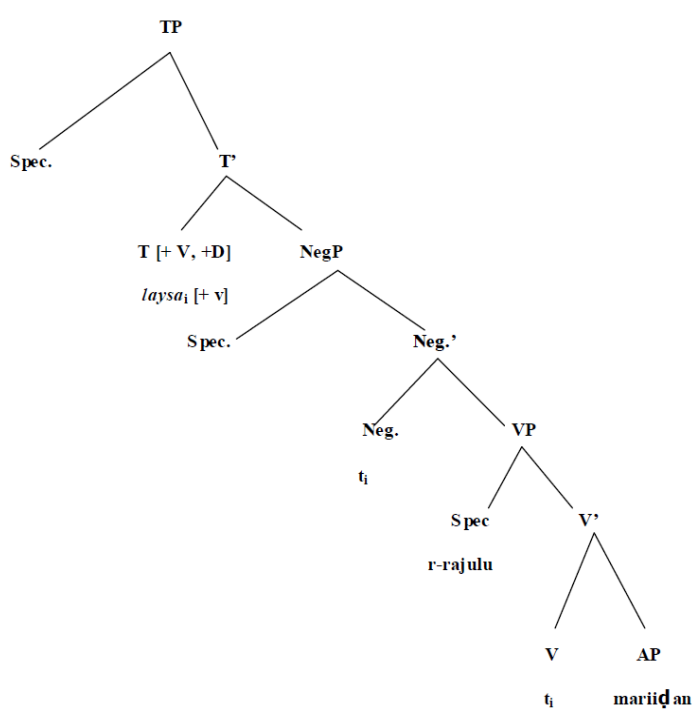


Since 'laysa' is inherently [+ present] and behaves like the copula, it can check the [+ V] feature of T.

However, the structure of negation in present tense sentences gets more complicated with the presence of a pronoun that agrees with the subject in person, number and gender, because in that case, the complement bears with either nominative or accusative case.

(76). laysa l-walad-u huwa 1-mujtahid-u

NEG-3MS the-boy-nom 3MS the-diligent-nom

'The boy he is not diligent.'

(77). laysa 1-walad-u huwa 1-mujtahid-a

NEG-3MS the-boy-nom 3MS the-diligent-acc

'The boy he is not diligent.'

'huwa' can be treated in MSA as agreement (AGR) as argued by Berman (1978) and Rapoport (1987) in their works on Hebrew. Rapoport assumes that 'AGR' is used in the equational sentences in Hebrew the same way the copula is used in English. Thus, sentence (76) can be illustrated as in (78).

(78).

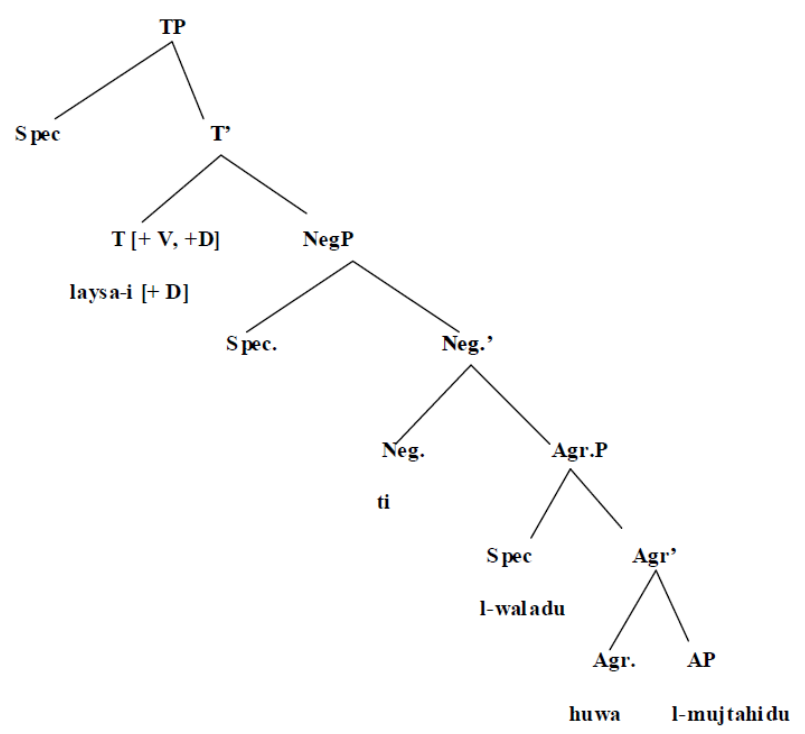

Copular sentences in JA are negated via the use of the negative particle 'ma. . . `' and/or 'ma'. Al-Tamari (2001)

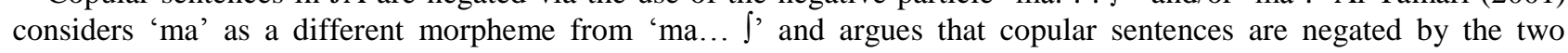
morphemes instead of one. Consider the following examples:

(79). a. T-Taqs ma-kaani-j kwaiis the-weather NEG-was-NEG good 'The weather was not beautiful.'
b. ma-kaani-f T-Taqs kwaiis
NEG-was-NEG the-weather good
'The weather was not beautiful.'

(80). a. T-Taqs ma-kaan kwaiis the-weather NEG-was good

'The weather was not beautiful.'
b. ma-kaan T-Taqs kwaiis
NEG-was-NEG the-weather good
'The weather was not beautiful.'

Sentence (79 b) is illustrated as in (81).

(81). 


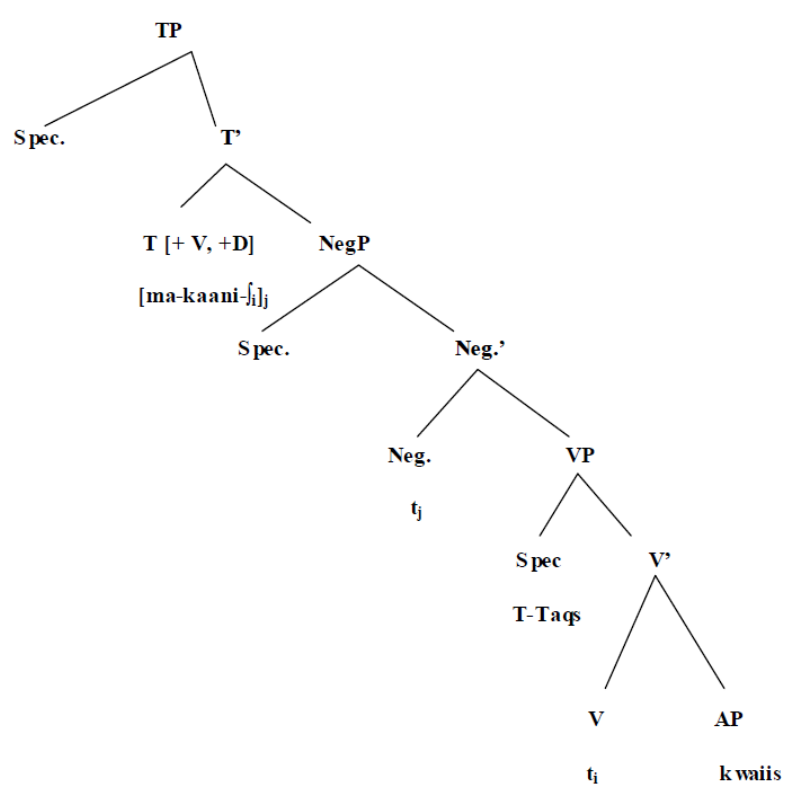

In (81), 'kaan' raises to Neg. to check the [+ D] feature, the complex head [ma-kaani-J] raises to T of TP and checks the $[+\mathrm{V}]$ feature. The subject remains in the Spec. of VP since it is not motivated to raise higher in the tree diagram.

Present tense sentences in JA behave exactly like present sentences in MSA in the sense that they lack the copula and thus are considered as verbless sentences. Onizan (2005) proposes that verbless sentences in JA are of two types, namely: predicative and equational sentences and both are similar in containing a subject and a predicate. The only difference between them is that equational sentences contain a pronoun that agrees with the subject according to person and number as can be seen in (82) and (83) respectively.

(82). Ahmad Tabiib

Ahmad doctor

'Ahmad is a doctor.'

(83). Ahmad huu Tabiib

Ahmad 3MS doctor

'Ahmad is a doctor.'

Regarding negation of verbless sentences whether equational or predicative, neither 'ma... J' nor 'ma' can be used. Instead, the negative particle 'mif' (not) is used. Consider the negation of (82) and (83) given below as (84) and (85).

(84). Ahmad mif Tabiib

Ahmad NEG doctor

'Ahmad is not a doctor.'

(85). Ahmad mif huu T-Tabiib

Ahmad NEG 3MS the-doctor

'Ahmad is not the doctor.'

\section{CONCLUSION}

This paper discussed the syntax of sentential negation in JA. JA has shown different negative particles, namely 'ma... ', 'ma', 'mif', and laa' which occur in the context of the past, present and future tenses respectively. The 'Neg.P Hypothesis', which claims that negative particles head their own functional projections and negation occurs between $\mathrm{TP}$ and VP, accounts successfully for sentential negation in JA. In verbal sentences, the verb cannot raise to T across negation because of minimality. However, the verb merges with the negative particle to check the [+ D] feature and the complex head moves to $\mathrm{T}$ to check the $[+\mathrm{V}]$ feature. In order to account for copular sentences in JA and MSA, it has been claimed that copular sentences in JA are negated via the use of the negative particle 'ma. . . J' and/or 'ma'; whereas, in verbless sentences that lack the copula, the negative particle 'mil' occurs independently. In MSA, however, copular sentences are negated in different ways using different negative particles; the negative particle 'ma' is used to negate past perfective forms, lam' used to negate past imperfective forms, and 'lan' to negate future tense sentences. As far as present tense sentences are concerned, the negative particle 'laysa' is used instead.

\section{REFERENCES}

[1] Abdel-Ghafer, O. (2003). Copular Constructions in Modern Standard Arabic, Modern Hebrew and English. Ph. D dissertation, University of Kansas. 
[2] Abulhaja, L. (1989). The Development of Negative Structures in Children: Evidence from Jordanian Arabic. Arab Journal for Humanities. 36: 343-372.

[3] Al-Tamari, E. (2001). Sentential Negation in English and Arabic: A Minimalist Approach. Ph.D dissertation. University of Kansas, Lawrence.

[4] Bahloul, R. M. (1996). Negation in French and Tunisian Arabic. In M. Eid (ed.), Perspectives on Arabic Linguistics VIII, $67-$ 83. Amsterdam and Philadelphia: John Benjamins.

[5] Bakir, M. (1980). Aspects of Clause Structure in Arabic. Ph.D dissertation, Indiana University, Bloomington.

[6] Benmamoun, E. (1992). Inflectional and Functional Morphology: Problems of Projection, Representation and Derivation. Ph.D dissertation, University of Southern California, Los Angeles.

[7] Benmamoun, E. (1996). Negative Polarity and Presupposition in Moroccan Arabic. In Perspectives on Arabic Linguistics, VIII, ed. Mushira Eid, 47-66. Amsterdam: John Benjamins.

[8] Benmamoun, E. (2000). The Feature Structure of Functional Categories: Comparative Study of Arabic Dialects. Oxford University Press.

[9] Berman, R. A. (1978). Modern Hebrew Structure. University Projects. Tel Aviv.

[10] Bloom, L. (1970). Language Development. Cambridge, MA: MIT Press.

[11] Brustad, K. (2000). The Syntax of Spoken Arabic: A Comparative Study of Moroccan, Egyptian, Syrian and Kuwaiti Dialects. Washington, DC: Georgetown University Press.

[12] Caubet, D. (1996). La Négation en Arabe Maghr'ebin. In La Négation en Berbére et en Arabe Maghrébin, eds. S. Chaker, and C. Caubet, 79-97. Paris: L'Harmattan.

[13] Chomsky, N. (1993). A Minimalist Program for Linguistic Theory. In The View from Building 20, eds. K. Hale and S. J. Keyser, 1-49. Cambridge, Mass.: MIT Press.

[14] Chomsky, N (1994). Bare Phrase Structure. MIT Occasional Papers in Linguistics, volume 5. Cambridge, Mass.: MIT Department of Linguistics and Philosophy.

[15] Chomsky, N. (1995). The Minimalist Program. Cambridge, Mass.: MIT Press.

[16] Chomsky, N. (2000). Minimalist Inquiries: The Framework. In Step by Step: Essays on Minimalist Syntax in Honor of Howard Lasnik, eds. Roger Martin, David Michaels, and Juan Uriagereka, 89-155. Cambridge, Mass.: MIT Press.

[17] Chomsky, N. (2001). Derivation by Phase. In Ken Hale: A Life in Language, ed. Michael Kenstowicz, 1-52. Cambridge, Mass.: MIT Press.

[18] Eid, M. (1991). Verbless Sentences in Arabic and Hebrew. In Perspectives on Arabic Linguistics III, eds. Bernard Comrie and Mushira Eid, 31-61. Amsterdam: John Benjamins.

[19] Fassi Fehri, A. (1993). Issues in the Structure of Arabic Clauses and Words. Dordrecht: Kluwer.

[20] Gleason, J. (2001). The Development of Language. Needham Heights, MA: Allyn and Bacon.

[21] Haegeman, L. (1995). The Syntax of Negation. Cambridge: Cambridge University Press.

[22] Jaradat, A. A. (2007). A Linguistic Analysis of Jordanian Proverbs; a Syntactic, Semantic and Contextual Study. Ph. D dissertation, University of Kansas.

[23] Kayne, R. (1989). Facets of Romance Past Participle Agreement. In P. Beninca (ed.), Dialects Variation and the Theory of Grammar, 85-103. Dordrecht: Foris.

[24] Laka, I. (1994). On the Syntax of Negation. New York: Garland Pub.

[25] Obeidat, H. and Farghal, M. (1994). On the Status of the Equational Sentences in the Grammar of Arabic. Abhath Al-Yarmouk, 12: 2, 9-35.

[26] Onizan, N. (2005). Function of Negation in Arabic Literary Discourse. Ph.D dissertation, University of Kansas.

[27] Ouhalla, J. (1991). Functional Categories and Parametric Variation. London: Routledge.

[28] Pollock, J. Y. (1989). Verb Movement, Universal Grammar, and the Structure of IP. Linguistic Inquiry 20, 365-424.

[29] Rapoport, T. (1987). Copular, Nominal, and Small Clauses: A Study of Israeli Hebrew. Ph.D dissertation, MIT, Cambridge, Massachusetts.

[30] Shlonsky, U. (1997). Clause Structure and Word Order in Hebrew and Arabic: An Essay in Comparative Syntax. Oxford: Oxford University Press.

[31] Zanuttini, R. (1997). Negation and Clausal Structure: A Comparative Study of Romance Languages. New York: Oxford University Press.

Islam M. Al-Momani was born in Irbid, Jordan in 1966. He holds a Ph.D degree in Linguistics/Syntax from Mumbai University/India in 1998, an M.A in Linguistics from Delhi University/India in 1992, and a B.A in English Language and Literature from Yarmouk University/Jordan in 1989.

$\mathrm{He}$ is currently working as an Assistant Professor in the Department of English Language and Literature at Al-Hussein Bin Tala University/Jordan. He has been teaching there since 2003. Over there, he worked as the head of the department for the academic year 2006/2007, a member of the Faculty of Arts Council for the academic years 2005/006 and 2006/2007, and a member of the University Council for the academic year 2007/2008. Before that, he worked for four years as an Assistant Professor in the Department of English Language and Literature at Al-Isra Private University/Jordan and also worked there as a coordinator for the Faculty of Arts in the Faculty of Evening Studies.

He has published several papers in Linguistics especially in the field of Syntax in international scientific journals. His research interests include Linguistics and Applied Linguistics, Syntax, Semantics, Contrastive Linguistics, and Sociolinguistics. 